FEBRUARY 2021 - VOL. 85 (1), NO. 556

MINERALOGICAL MAGAZINE [3]

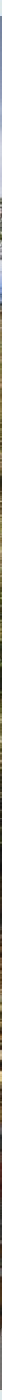

\title{
Frank Reith Memorial Issue
}

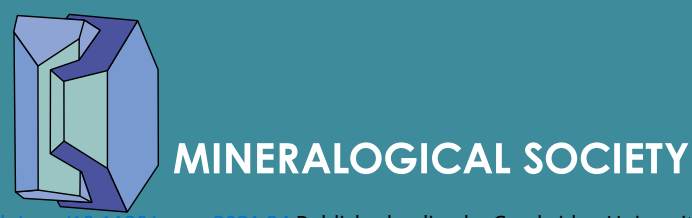




\title{
MINERALOGICAL MAGAZINE \\ ISSN 0026-461X
}

\author{
Principal Editors \\ Stuart J. Mills, Museums Victoria, Melbourne, Australia \\ Roger H. Mitchell, Department of Geology, Lakehead University, Thunder Bay, \\ Ontario P7B 5E1, Canada
}

(Manuscripts should be submitted on-line at http://www.editorialmanager.com/minmag/)

Structures Editor: Peter Leverett, University of Western Sydney, Australia

Production Editor: Helen C. Kerbey, Mineralogical Society of Great Britain and Northern Ireland

Makoto Arima, Yokohama National University, Japan Daniel Atencio, University of São Paulo, Brazil

Ferdinando Bosi, Sapienza, University of Rome, Italy

Sam Broom-Fendley, Camborne School of Mines, UK

Casey Bryce, University of Bristol, UK

Aniket Chakrabarty, Indian Institute of Science Education and

Research Tirupati, India

Andrew Christy, University of Queensland, Australia

Claire Corkhill, University of Sheffield, $U K$

Ian Coulson, University of Regina, Canada

Eimear Deady, British Geological Survey, UK

Giancarlo Della Ventura, Roma Tre University, Italy

Irina Galuskina, University of Silesia, Poland

G. Diego Gatta, University of Milan, Italy

Charles Geiger, University of Salzburg, Austria

David J Good, University of Western Ontario, Canada

Ian Graham, University of New South Wales, Australia

Edward Grew, University of Maine, USA

Jason Harvey, University of Leeds, UK

David Hibbs, University of Sydney, Australia

\section{Associate Editors}

Mihoko Hoshino, National Institute of Advanced Industrial Science and Technology, Japan

Anthony Kampf, Natural History Museum of Los Angeles County, USA

Sergey Krivovichev, St Petersburg State University, Russia

František Laufek, Czech Geological Survey, Czech Republic

Martin Lee, University of Glasgow, UK

Juan Liu, Peking University, China

Juraj Majzlan, University of Jena, Germany

Leone Melluso, University of Naples Federico II, Italy

Koichi Momma, National Museum of Nature and Science, Japan

Thomas Mueller, Georg-August-University Göttingen, Germany

Katherine Pfaff, Colorado School of Mines, USA

Michael Rumsey, Natural History Museum, UK

Oleg Siidra, St Petersburg State University, Russia

Craig Storey, University of Portsmouth, UK

Elena Zhitova, Institute of Volcanology and Seismology RAS, Russia

Runliang Zhu, Guangzhou Institute of Geochemistry, China

\section{MINERALOGICAL SOCIETY}

[Registered Charity No. 233706]

Officers and Council for 2021

President: J. Lloyd

Treasurer: J. Harvey P.R.O.: R. J. Bowell General Secretary: J. M. Horák

Principal Editors of the Magazine: S. J. Mills, R. H. Mitchell

Principal Editor of 'Clay Minerals': G. E. Christidis

Ordinary Members of Council: J.F.W. Bowles, F. Cooper, J. Darling, E. Deady, S. Gibson, N. Gray-Wannell, C. Mottram, A. Neumann, L. Newsome, K. Olsson-Francis, C. Pearce, M. Rumsey, M. Smith,

R. Taylor, A. Thomson, M. Widdowson, D. Wray

Office address: 12 Baylis Mews, Amyand Park Road, Twickenham TW1 3HQ, UK

Website: www.minersoc.org

Tel.: +44 (0)20 8891 6600; Fax: +44 (0)20 8891 6599; e-mail: info@minersoc.org

Mineralogical Magazine is published six times per year in February, April, June, August, October and December. The Journal is now primarily an online one.

The subscription price (excluding VAT) to Mineralogical Magazine for volume 85 (2021), which includes print and electronic access, is $\mathfrak{£} 816$ (USA, Canada and Mexico US\$1057) and includes delivery by air; single parts are available at $£ 157$ (USA, Canada and Mexico US\$203) plus postage. The electronic-only price available to institutional subscribers is $£ 632$ (USA, Canada and Mexico US\$817). EU subscribers (outside the UK) who are not registered for VAT should add VAT at their country's rate. VAT registered subscribers should provide their VAT registration number. Orders, which must be accompanied by payment, may be sent to any bookseller or subscription agent or direct to the publishers: Cambridge University Press, UPH, Shaftesbury Road, Cambridge CB2 8BS, or in the USA, Canada, and Mexico to Cambridge University Press, Journals Fulfillment Department, 1 Liberty Plaza, Floor 20, New York, NY 10006, USA. Japanese Prices for institutions are available from Kinokuniya Company Ltd, P.O. Box 55, Chitose, Tokyo, Japan.

All subscription enquiries should be sent to: journals@cambridge.org

Front cover picture: Frank Reith recovering gold for biogeochemical analysis at Lemmenjoki, Finland (13/8/2013). 